\title{
REPRESENTAÇÕES DE TIPOS DE FEMINILIDADES E MASCULINIDADES EM GAMES: IDENTIDADES DE GÊNERO E ESTEREÓTIPOS
}

\section{Representations of types of femininities and masculinities in games: identity of gender and stereotypes.}

\author{
Juliana Saldanha Romanus ${ }^{25}$ \\ Marinês Ribeiro dos Santos ${ }^{26}$
}

\section{Resumo}

Tomando os vídeo games como uma área relevante para os estudos da cultura visual, pretendemos discutir alguns tipos de feminilidades presentes nesse universo, que reforçam estereótipos de gênero. A orientação teórica adotada tem como base os Estudos Culturais e sua análise crítica das construções imagéticas, de onde nos apropriamos dos conceitos de representação cultural, identidade e estereótipos. Recorremos, também, aos Estudos de Gênero, com o intuito de discutir as relações de poder envolvidas na afirmação de feminilidades hegemônicas. A partir da apresentação

25 Atualmente participa do Programa de Pós-Graduação em Design (PPGDesign) da Universidade Federal do Paraná (UFPR), estudando relações entre colaboração e jogos eletrônicos. Possui graduação em Design Gráfico pela Universidade Tecnológica Federal do Paraná (2012). Tem experiência na área de Desenho Industrial, com ênfase em Programação Visual. E-mail: juliana.romanus@gmail.com Tecnologia pela Universidade Tecnológica Federal do Paraná (2000) e Doutorado em Ciências Humanas pela Universidade Federal de Santa Catarina (2010). É professora do Departamento Acadêmico de Desenho Industrial e do Programa de Pós-Graduação em Tecnologia na Universidade Tecnológica Federal do Paraná. Seus interesses de pesquisa estão focados nos Estudos em Design, com ênfase na cultura material e suas interfaces com o espaço doméstico e com as relações de gênero. Sua tese de doutoramento, intitulada \&quot;O Design Pop no Brasil dos Anos 1970: Domesticidades e relações de gênero na revista Casa e Jardim\&quot; foi contemplada com o primeiro lugar no 24 Premio Design Museu da Casa Brasileira, na categoria destinada aos trabalhos acadêmicos. E-mail: riberio@utfpr.edu.br 
das personagens femininas dos games de ação Tomb Raider e Metróide, problematizamos alguns discursos recorrentes nas representações de feminilidades, assim como identificamos propostas de novas possibilidades de representações capazes de desestabilizar o caráter "natural" das formas de olhar e interpretar as imagens de corpos femininos.

Palavras-chave: Relações de gênero, Representações culturais, Estereótipos e Vídeo Games.

\section{Abstract}

Taking video games as an area relevant to the visual culture studies, we intend to discuss some types of femininity present in this universe, that reinforce gender stereotypes. The theoretical orientation adopted is based on Cultural Studies and critical analysis of the images constructs, where we appropriate the concepts of cultural representation, identity and stereotypes. Was recalled, also, the Gender Studies, in order to discuss the power relations involved in the assertion of hegemonic femininity. From the presentation of the female characters of the action games Tomb Raider and Metroide, problematize some speeches recurring representations of femininity, as well as proposals to identify new possibilities for representations capable of destabilizing the character "natural" ways of seeing and interpreting the images female bodies.

Keywords: Gender relations, Cultural representations, Stereotypes and Games.

\section{Introdução}

Este artigo é resultado de uma pesquisa mais ampla, que busca entender algumas das representações de tipos de masculinidades e feminilidades nos personagens de games que podem reforçar estereótipos de gênero. Os games são parte integrante da cultura visual e possuem um papel importante nas práticas de significação e posicionamento de sujeitos. Nos games, a forma como são apresentadas algumas características e como valores são colocados em evidência, podem servir como âncoras de identificação ou diferenciação dos indivíduos, contribuindo na construção de identidades.

Como sugere Stuart Hall (1997), a partir de meados do séc. XX, a "virada cultural" vem orientando a prática das ciências humanas e sociais. Com 
essa virada os paradigmas de estudos sobre a cultura têm que ser expandidos. Portanto, conta-se com novos tipos de suporte para representações, como objeto de investigação. As pesquisas sobre games localizam-se nesse contexto e os estudos nessa área ainda são muito recentes. No livro "Mapa do Jogo: A diversidade cultural dos games" organizado por Lucia Santaella e Mirna Feitoza (2008), há uma sessão intitulada "Games: emergência de um campo teórico". A sessão reforça exatamente a ideia de que há poucos estudos no campo dos games.

Game é definido aqui como todo jogo computacional eletrônico, ou seja, aqueles que exigem uma interface eletrônica de interação com o/a jogador/a. Os games podem ser divididos em três grandes grupos: games para arcades, popularmente conhecidos como fliperamas; games para computador; e games para console, tais como Xbox, Playstation, NintendoWii (SANTAELLA; FEITOZA, 2009).

Para entender o conceito de identidade de gênero, adotamos a abordagem de Guacira Lopes Louro (2001). Dialogando com Stuart Hall, a autora considera os processos de constituição das identidades como históricos e contingentes e adapta essa visão para o entendimento das identidades de gênero. Nas palavras da autora "compreendemos os sujeitos como tendo identidades plurais, múltiplas, identidades que se transformam que não são fixas ou permanentes, que podem até mesmo ser contraditórias" (LOURO, 2001, p. 24). Ou seja, não existe o feminino ou o masculino, como singulares, fixos e independentes. Os significados dessas categorias são construídos historicamente, culturalmente e socialmente, apropriados pelos indivíduos no intercurso social, sempre perpassados por outras características identitárias.

As representações exercem papel de pedagogias do feminino e masculino e são os processos sociais envolvidos em relações de poder que fundamentam os valores culturais atribuídos às representações. Nos jogos eletrônicos, assim como na publicidade e nas artes, as muitas das características colocadas em evidência na formação dos personagens pressupõem um espectador masculino heterossexual. Ao referir-se à mídia brasileira, lara Beleli (2007) comenta que um grande número de peças publicitárias celebra e naturaliza um corpo feminino sem voz, um corpo-objeto do olhar. Esse olhar, construído a partir de um ponto de vista masculino e heterosse- 
xual, é apresentado como algo natural. Mulheres e homens podem ocupar o espaço desse sujeito observador, sem mesmo questionar ou pensar em outras possibilidades de ver (BERGER, 1974).

\section{Representações culturais e os jogos de ação}

As questões discutidas na seção anterior podem ser facilmente observadas no universo dos jogos eletrônicos, onde percebemos uma forma recorrente de representação dos corpos femininos. Por exemplo, no jogo Tomb Raider, a personagem denominada Lara Croft (Figura 1) sofreu um processo de sensualização do corpo ao longo dos anos, que veio acompanhado do aperfeiçoamento das técnicas de modelagem 3D. Recentemente, em um canal do youtube, no qual os apresentadores demonstram alguns lançamentos de jogos, Alexandre Ottoni (JovemNerd), define a mais nova versão do game como ideal para "Fap!Fap!Fap!", o que na linguagem da internet é uma expressão indicativa do ato da masturbação masculina. O jogo é visto dessa maneira, pois com a evolução das tecnologias de modelagem, a personagem é construída com o intuito de simular uma mulher "real". A imagem da personagem remete ao tipo de feminilidade ideal, de acordo com uma abordagem baseada no imaginário masculino hegemônico. Além disso, mesmo sendo uma aventureira, Lara Croft usa roupas curtas e pequenas, que favoreçam a evidência das curvas de seu corpo. Durante o jogo são feitos diversos closes no decote da personagem.

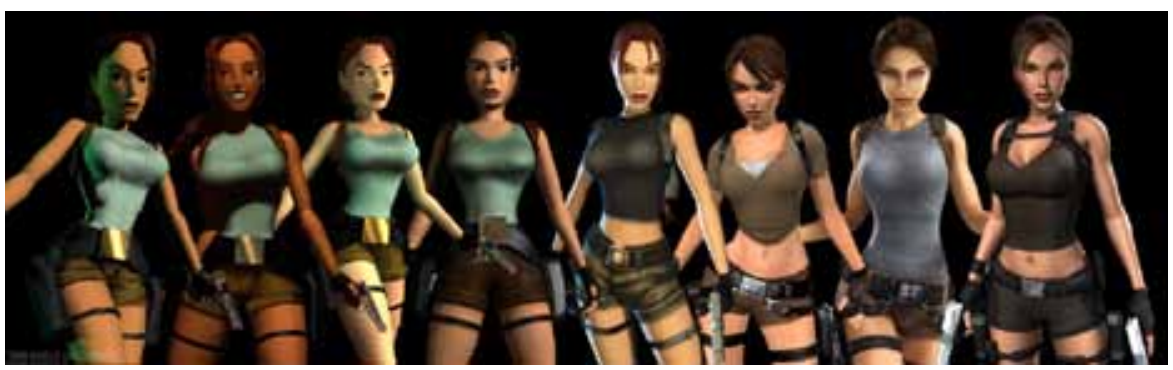


Conforme foi comentado anteriormente, o que faz com que certas representações culturais sejam vistas como "naturais" são os processos sociais imbricados em relações de poder. Guacira Lopes Louro (2001), explica que o gênero é produzido nas e pelas relações de poder. Estão em jogo os mecanismos de poder acionados para se estabilizar e tentar manter em uso determinados tipos de representação em detrimento de outros. Os estereótipos são usados principalmente para definir e limitar os significados atribuídos às identidades sociais. A partir da repetição de certas de representações culturais, se moldam os estereótipos, e a partir deles são definidas as "normas", em termos de expectativas sociais. Os limites estabelecidos pelos discursos e práticas normativas classificam quem se encaixa neles e quem está fora, ou seja, o que é considerado desviante. Louro (2001) afirma que a existência desse "outro" é necessária, pois as identidades ditas "normais" precisam das identidades "subjugadas" para se afirmar e para se definir. Sua afirmação se dá na medida em que contrariam e rejeitam o que é apresentado como o seu contrário.

Os estereótipos são construídos mediante o uso de características fáceis de compreender de lembrar, amplamente compartilhadas. Operam no sentido de reduzi as pessoas ou os grupos sociais a tais peculiaridades, muitas vezes exagerando-as, simplificando-as e fixando-as como imutáveis. Assim, reduzindo as identidades culturais a um conjunto simples de características essenciais, naturais e fixas, a estereotipação facilita reunir todas aquelas que correspondem à "norma" em uma "comunidade imaginada", ao mesmo tempo em que estigmatiza simbolicamente as "outras" que são de alguma forma, consideradas como diferentes (SANTOS; PEDRO, 2001). A identificação com determinadas representações muitas vezes é guiada pelo desejo de corresponder a certos padrões que são estabelecidos e mantidos pelas relações de poder, e assim considerados como "certos" e "aceitáveis".

Conforme já foi dito, Louro (2001) afirma que somos sujeitos de identidades transitórias e contingentes. Portanto, as identidades sexuais e de gênero - tal como todas as identidades sociais - têm caráter fragmentado, instável, histórico e plural. Para reforçar seu argumento a autora recorre à afirmação de Tomás Tadeu da Silva (1998, Apud Louro, 2001, p. 16), que diz: 
Os diferentes grupos sociais utilizam a representação para forjar a sua identidade e as identidades dos outros grupos sociais. Ela [a representação] não é, entretanto, um campo equilibrado do jogo. Através da representação se travam batalhas decisivas de criação e imposição de significados particulares: esse é um campo atravessado por relações de poder. [...] o poder define a forma como se processa a representação; a representação, por sua vez, tem efeitos específicos ligados, sobretudo, à produção de identidades culturais e sociais, reforçando, assim, as relações de poder.

Um fã do game Tomb Raider, que também é artista digital, criou há quatro anos uma versão masculina da personagem Lara Croft (Figura2). Essa versão se tornou popular e vem sendo comentada nas redes sociais nos últimos tempos. Em entrevista, o artista Raffael declara ser muito Fã do game. Contudo, pelo fato de ser gay, afirma que gostaria de propor uma versão da personagem que tivesse mais alinhada com os seus interesses. Em princípio, ele esperava que tudo fosse visto como uma brincadeira e que rendesse algumas risadas. Raffael percebe a sexualização da personagem Lara Croft como exagerada e ressalta os antagonismos nas representações de personagens masculinos e femininos nos vídeo games, não só quanto às características corporais e de vestimentas, mas também em relação aos movimentos e à linguagem corporal. 

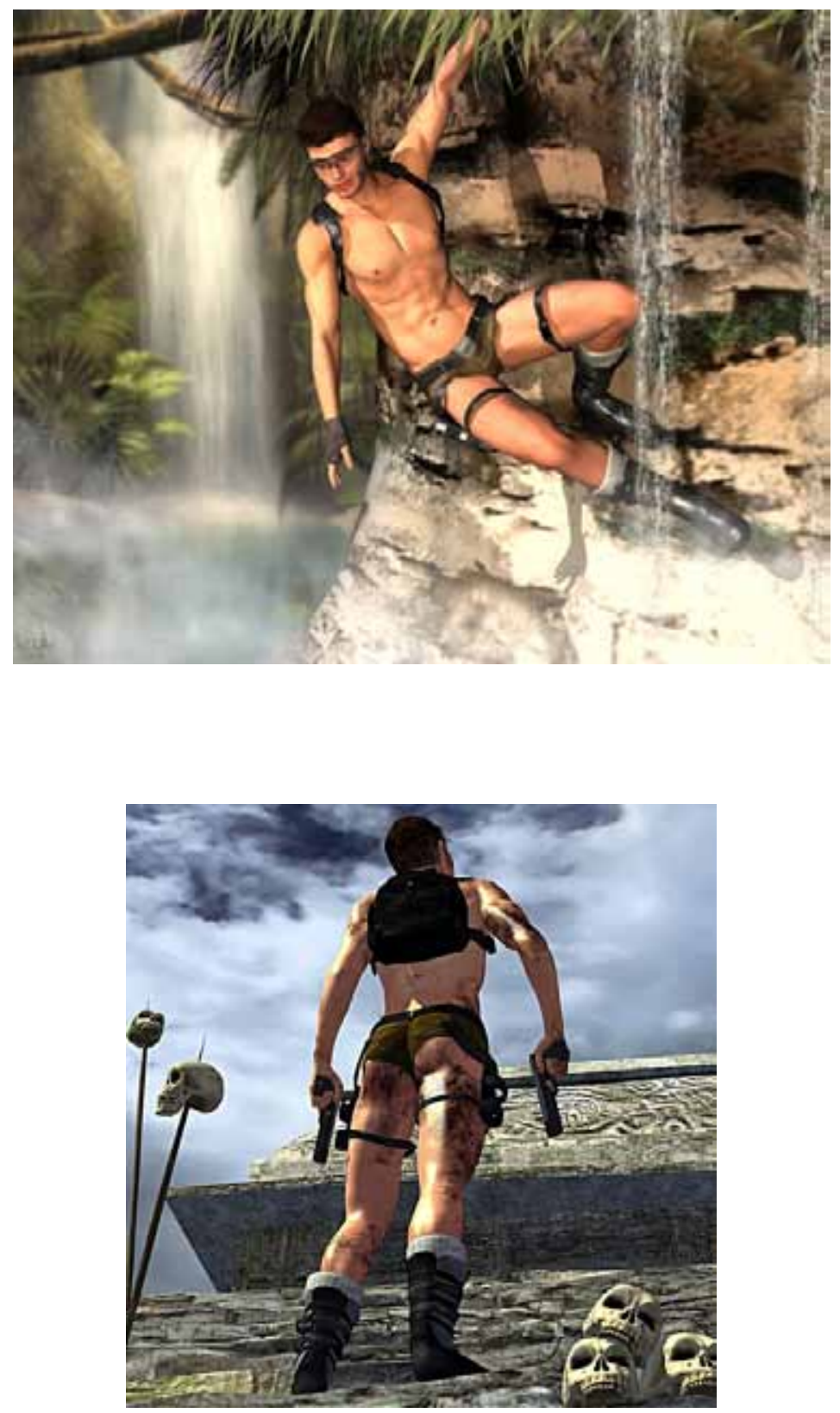
Independentemente das intenções de Raffael, o seu trabalho possibilita uma perspectiva diferente. A partir do contraste com versão masculina da personagem, o olhar treinado para aceitar apenas a imagem feminina com certo tipo de corpo, vestes e comportamento pode ser questionado. Não se tratam de questionamentos relacionados à determinação do que seria certo ou errado, mas sim quanto a novas propostas de olhar.

De acordo com John Berger (1974, p.66), que analisa as representações de corpos femininos nos cânones das artes visuais ocidentais, a muIher é representada de uma maneira bastante diferente do homem. Não porque o feminino seja em "essência" diferente do masculino, mas porque se privilegia sempre que um tipo específico de espectador 'ideal', entendido como um sujeito masculino heterossexual. Sendo assim, a imagem da muIher é construída com o objetivo agradá-lo.

Identificar-se com certa representação estabelece uma relação de pertencimento. Todas as representações e as práticas ligadas a elas estabelecem padrões de sujeitos masculinos e femininos marcando entre eles relações de diferença. Somos treinados para reconhecer e classificar esses padrões, assim como os sujeitos que os portam. Classificamos os sujeitos sociais a partir da forma como se expressam, pelos seus gestos, como se vestem, a que grupo aparentam pertencer e, a partir disso, os julgamos como "adequados" ou "diferentes". As muitas formas de se fazer mulher ou homem, as várias possibilidades de viver prazeres e desejos corporais são sempre sugeridas, anunciadas, promovidas socialmente. Porém, elas também são renovadamente reguladas, condenadas ou negadas (LOURO, 2001).

Historicamente, no mundo dos games há uma recorrência da representação de personagens femininas sexualizadas. Vejamos como mais um exemplo, o jogo Metróide de 1985. Neste título, a personagem Samus é emulável ${ }^{27}$. No início da partida, ela veste uma armadura cinza que cobre todo o corpo. Contudo, se o jogador consegue vencer todos os desafios, ela se despe, ficando apenas com um biquíni (Figura3). Mesmo com a qualidade gráfica do jogo sendo muito baixa, a intenção é oferecer o corpo feminino como prêmio.

27 Emulável significa que o jogador/a pode controlar o/a personagem do jogo, podendo este ser protagnista ou não da trama. 

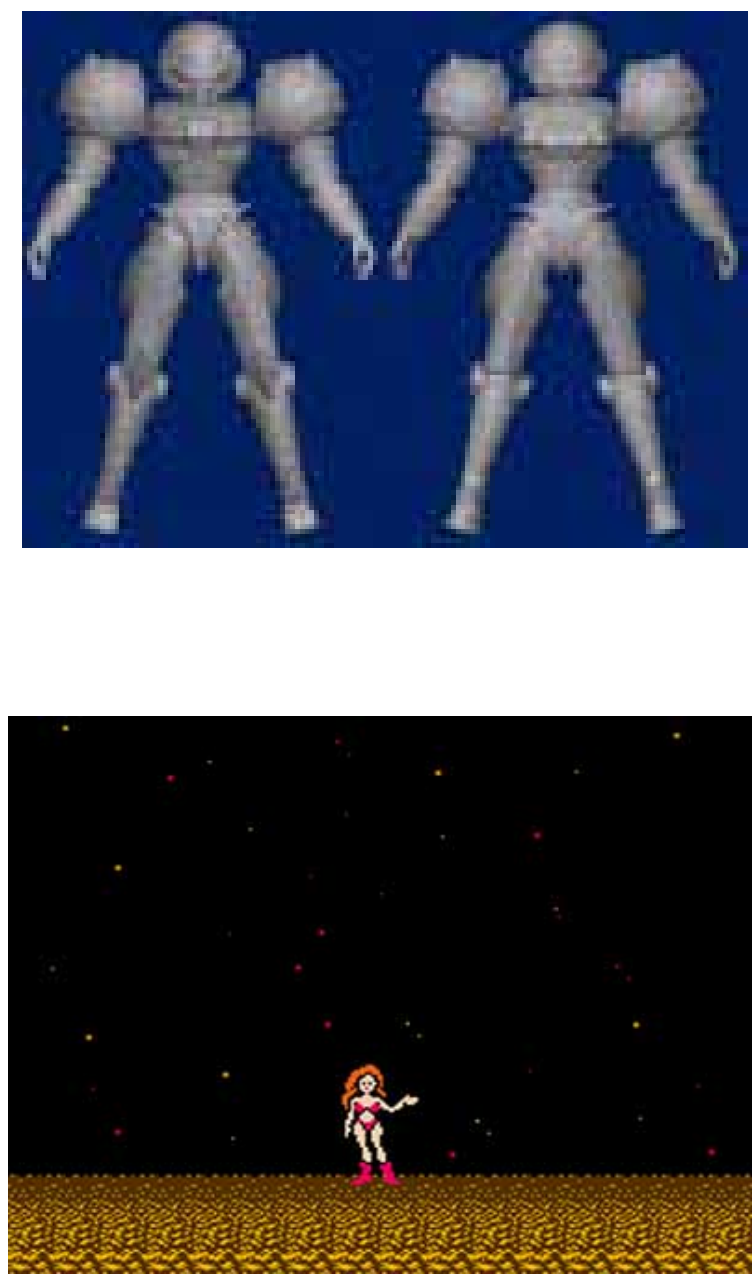

Loponte (2002, p. 290) considera que, por seu caráter ativo, a visão talvez seja o sentido que melhor expresse a presença e a eficácia do poder. Muitas das operações próprias das relações de poder se realizam e se efetivam no olhar ou por meio dele. Nas representações visuais, a mediação pelo olhar é fundamental para que homens transformem mulheres em objeto de prazer escópico, imobilizadas e disponíveis para desfrute e consumo. 
No universo dos games, mesmo que em alguns momentos haja espaço para representações contestatórias e desviantes, como na proposta do artista Raffael, as representações recorrentes ainda correspondem às formas tradicionais de construção das personagens, levando em conta os tipos de feminilidades e masculinidades posicionados como hegemônicos.

\section{Considerações finais}

A partir do estudo do universo dos vídeo games, podemos perceber certas repetições de padrões hegemônicos na construção de tipos de feminilidades e masculinidades. Essas representações estabelecem as características do "feminino" associadas principalmente à sensualidade e nudez, definindo o estereótipo do corpo feminino sexualizado. Quando essas características são transferidas para um personagem masculino causam sensação de estranhamento, mas também abrem espaço para discussões e novas visões.

Precisamos ficar atentos, no entanto, para não entender que uma visão diferente seria mais ou menos correta do que a que é vigente. Trata-se de pensar sobre o modo de olhar com o objetivo romper com as verdades cristalizadas como "verdades únicas", questionar a "naturalidade" dos discursos e convidar para a pluralidade de pensamento ao denunciar as formas de poder exercidas sobre e pelos sujeitos e instituições sociais.

É importante ressaltar ainda que a afirmação, de estereótipos de gênero, produz potencialmente, espaço para leituras dissonantes, gerando contestação e impulsionando mudanças de paradigma. É necessário entender que o campo das representações e da construção de identidades, está constantemente se modificando e se reformulando. Cabe às pessoas que se confrontam com as representações o compromisso com a leitura crítica dos valores veiculados e o constante exercício de questionar e reinterpretar os modelos oferecidos.

\section{Referências}


BELELI, lara. Corpo e Identidade na propaganda. Florianópolis: Revista Estudos Feministas 15 (1), janeiro-abril/2007, p.193-215.

BERGER, John. Modos de ver.Barcelona: Gustavo. Gili, 1974.

HALL, Stuart. A centralidade da cultura: notas sobre as revoluções culturais do nosso tempo. Educação \& Realidade, Porto Alegre, vol. 22, n, 2, jul./dez, 1997, p. 15-46.

LOPONTE, Luciana Gruppelli. Sexualidades, artes visuais e poder: pedagogias visuais do feminino. Revista Estudos Feministas, jul.-dez., vol.10, n. 2. UFRJ, Rio de Janeiro, p. 283-300.

LOURO, Guacira Lopes. Gênero Sexualidade e Educação: uma perspectiva pós-estruturalista. São Paulo: Vozes, 2001.

OTTONI, Alexandre. JovemNerd: Nerdplayer 79 - Tomb Raider. Disponível em: <http://www.youtube.com/watch?v=W_IDjHNIVFs> Acesso em: 04 jul 2013.

SANTAELLA, Lucia; FEITOZA Mirna (orgs.). Mapa do jogo. São Paulo: Cengage Learning, 2008.

SANTOS, Marinês Ribeiro dos; PEDRO, Joana Maria. Estratégias discursivas e identidades de gênero: a construção da "dona de casa moderna" na revista Casa \& Jardim dos anos 1960. Caderno Espaço Feminino, Uberlândia/MG, vol. 24, n. 1, Jan./Jun. 2011, p. 163-184.

STARR, Michele. Meet Larry Croft: if Lara was a man. Disponível em: $<$ http://www.cnet.com.au/meet-larry-croft-if-lara-was-a-man-339344728. htm\#image0> Acesso em: 05 jul 2013. 